\title{
PENGARUH SOSIAL EKONOMI TERHADAP KEPEMILIKAN ASURANSI KESEHATAN MASYARAKAT DESA KEBUMEN KECAMATAN BANYUBIRU KABUPATEN SEMARANG
}

\author{
Tika Melinda ${ }^{1}$, Nunik Wahyuni ${ }^{2}$, Surya Tri Handoko ${ }^{3}$, Sulis Safitri ${ }^{4}$, Nurul \\ Zakhra Utami $^{5}$, Ikhwan Noor Yusfiansyah ${ }^{6}$, Febrian Adhira Riyadi Putro ${ }^{7}$ \\ 1,2,3,4,5,6,7 Program Studi Pendidikan Geografi Fakultas Keguruan dan Ilmu Pendidikan Universitas \\ Muhammadiyah Surakarta \\ J1. A. Yani, Mendungan, Pabelan, Kec. Kartasura, Kabupaten Sukoharjo, Jawa Tengah 57162 \\ Alamat e-mail: ${ }^{1}$ tikamelinda06@gmail.com
}

\begin{abstract}
Abstrak
Asuransi adalah suatu institusi yang direncanakan guna menangani risiko. Asuransi kesehatan memiliki fungsi penting dalam memberikan jaminan kesehatan yang menyeluruh bagi rakyat Indonesia agar penduduk Indonesia dapat hidup sehat, produktif, dan sejahtera. Pengetahuan masyarakat tentang asuransi kesehatan berpengaruh terhadap tingkat sosial ekonomi seperti pendidikan, pekerjaan dan pendapatan. Penelitian ini merupakan penelitian deskriptif kuantitatif dan populasi penelitian adalah masyarakat Desa Kebumen, Banyubiru, Semarang dengan jumlah sampel 320 orang. Metode analisis yang digunakan analisis multivariat dengan tingkat signifikansi $5 \%$. Hasil penelitian menunjukan 52\% masyarakat sudah memiliki asuransi kesehatan serta nilai pada uji regresi linier berganda p-value 0,000 yang artinya ada pengaruh sosial ekonomi dengan kepemilikan asuransi kesehatan.
\end{abstract}

Kata Kunci: pendidikan; pekerjaan; pendapatan; kepemilikan asuransi kesehatan;

\begin{abstract}
Insurance is an institution that is planned to deal with the risk. Health insurance has an important function in providing comprehensive health coverage for Indonesian to Indonesian people can live healthy, productive and prosperous. Community knowledge of health insurance affects the socio-economic level, such as education, employment, and income. This research is a quantitative and descriptive study population is villagers in Kebumen, Banyubiru, Semarang with a sample of 320 people. The analytical method used multivariate analysis with a significance level of $5 \%$. The results showed 52\% of people already have health insurance and the value of the linear regression test p-value of 0.000, which means there is socio-economic influence with the ownership of health insurance.
\end{abstract}

Keywords: education; employment; income; health insurance ownership;

\section{PENDAHULUAN}

Salah satu upaya negara dalam meningkatkan kesejahteraan bagi seluruh masyarakat Indonesia yaitu dengan cara menerapkan Jaminan Kesehatan Nasional (JKN). JKN ditargetkan agar dimiliki oleh seluruh seluruh masyarakat Indonesia tanpa terkecuali pada tanggal 1 Januari 2019. Menurut Dinas Kesehatan Jawa Tengah pada Tahun 2017, jumlah peserta JKN Provinsi Jawa Tengah sebanyak 25.715.793 jiwa atau 75,07\% dari total populasi di Provinsi Jawa Tengah. Jenis 
asuransi kesehatan terbagi menjadi dua, yaitu asuransi kesehatan swasta dan asuransi kesehatan negeri.

Asuransi kesehatan memiliki fungsi penting dalam memberikan jaminan kesehatan yang menyeluruh bagi rakyat Indonesia agar penduduk Indonesia dapat hidup sehat, produktif, dan sejahtera. Indonesia memiliki jumlah penduduk kurang lebih 250 juta jiwa, namun hanya 148 juta jiwa $(63,18 \%)$ yang memiliki asuransi kesehatan, berarti sekitar 102 juta jiwa penduduk Indonesia yang belum memiliki asuransi kesehatan (Maharani, 2015). Jumlah perusahaan asuransi di Indonesia setiap tahunnya terus meningkat. Pada tahun 2012 terdapat sekitar 140 perusahan asuransi, sementara dalam lima tahun meningkat menjadi 146 perusahaan asuransi dan reasuransi di tahun 2016. Selain itu, perusahaan penunjang asuransi juga mengalami peningkatan dari 205 perusahaan di tahun 2012 menjadi 237 perusahaan di tahun 2016. (Sari, 2017)

Jenis asuransi kesehatan terbagi menjadi dua, yaitu asuransi kesehatan swasta dan asuransi kesehatan negeri. Asuransi kesehatan swasta diantaranya yaitu Prudential, AXA, Manulife, Allianz, Sinarmas dan lain sebagainya. Asuransi kesehatan yang termasuk dalam kelompok negeri salah satu contohnya yaitu Badan Penyelenggara Jaminan Sosial Kesehatan (BPJS Kesehatan). Asuransi kesehatan memiliki beberapa tingkatan atau level terkait pelayanan fasilitas, misalnya dalam asuransi kesehatan BPJS Kesehatan ada tiga tingkatan fasilitas yaitu Kelas I, Kelas II, dan Kelas III. Masyarakat yang memiliki status ekonomi menengah ke atas cenderung menggunakan asuransi swasta karena pelayanan dalam program asuransi tersebut dinilai lebih baik.

Kesadaran masyarakat tentang asuransi berkaitan dengan faktor sosial ekonomi. Pertumbuhan sosial ekonomi di Indonesia dari waktu ke waktu memiliki dampak besar pada kehidupan masyarakat. Hal tersebut mempengaruhi pola pikir dan pola hidup masyarakat Indonesia untuk menempuh pendidikan maupun pekerjaan yang lebih baik agar mendapatkan penghasilan yang cukup.

Berdasarkan fakta dan temuan data awal, maka peneliti akan meneliti apakah masyarakat Desa Kebumen, Kecamatan Banyubiru sudah menjadi peserta pada program Jaminan Kesehatan Nasional (JKN). Sebelumnya pemerintah 
menargetkan bahwa seluruh rakyat Indonesia sudah menjadi peserta JKN pada 1 Januari 201. Tujuan dari penelitian ini adalah mengetahui pengaruh antara pendidikan, pekerjaan dan pendapatan terhadap kepemilikan asuransi di Desa Kebumen, Kecamatan Banyubiru, Kabupaten Semarang.

\section{METODE}

Jenis penelitian ini adalah penelitian deskriptif kuantitatif yang digunakan untuk meneliti populasi atau sampel tertentu, pengumpulan data menggunakan instrumen penelitian, analisis data bersifat kuantitatif dengan tujuan untuk menguji hipotesis yang telah ditetapkan (Siregar, 2013). Populasi penelitian yaitu masyarakat Desa Kebumen, Kecamatan Banyubiru, Kabupaten Semarang. Teknik penentuan jumlah populasi menggunakan persil bangunan yang diperoleh dari hasil citra google maps, sebanyak 1593 persil. Variabel independent pada penelitian ini adalah sosial ekonomi sedangkan variabel dependent penelitian ini adalah kepemilikan asuransi kesehatan. Analisa pada penelitian ini menggunakan analisa multivariat dengan uji $\mathrm{F}$ hitung ( $p$-value $<0,05$ ) yang artinya ada pengaruh sosial ekonomi dengan kepemilikan asuransi kesehatan secara bersamaan.

Teknik pengambilan sampel menggunakan teknik random sampling, dengan cara peneliti mengambil data peta persil persebaran permukiman yang sudah dibuat sebelumnya. Persil tersebut dimasukkan ke dalam rumus Slovin dengan tingkat signifikansi 5\%, sehingga didapatkan sampel data sejumlah 320. Sampel tersebut kemudian diolah ke dalam Microsoft Excel, dan diimplementasikan melalui software ArcMap 10.2.2. Data tersebut kemudian dipindahkan melalui aplikasi carry map untuk memudahkan peneliti dalam mencocokkan lokasi maupun sampel dengan menggunakan smartphone. Peneliti menggunakan metode observasi, wawancara dan dokumentasi sebagai pengumpulan data. Instrumen penelitian utama menggunakan kuesioner tertutup serta instrumen pendukungnya yaitu kamera, perekam suara, peta persil dan aplikasi carry map. 


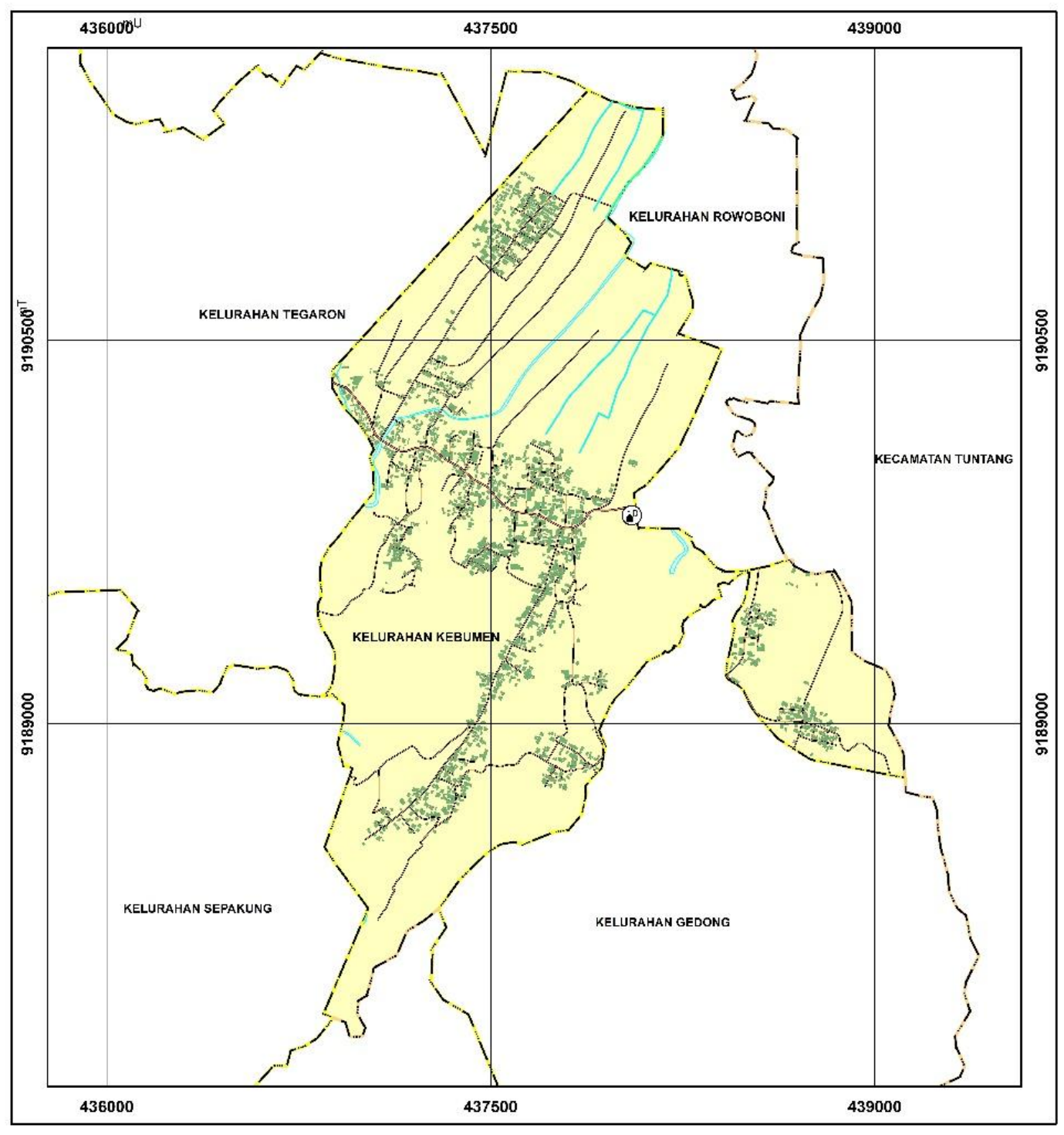

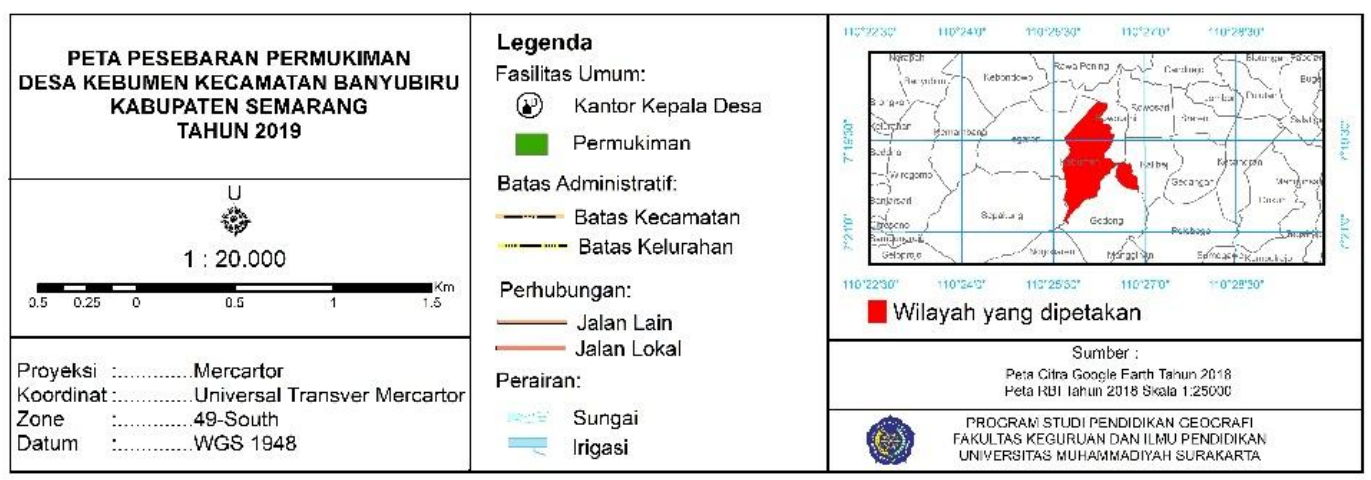

Gambar 1. Peta Persil Persebaran Permukiman 


\section{HASIL DAN PEMBAHASAN}

\section{Sosial Ekonomi Desa Kebumen}

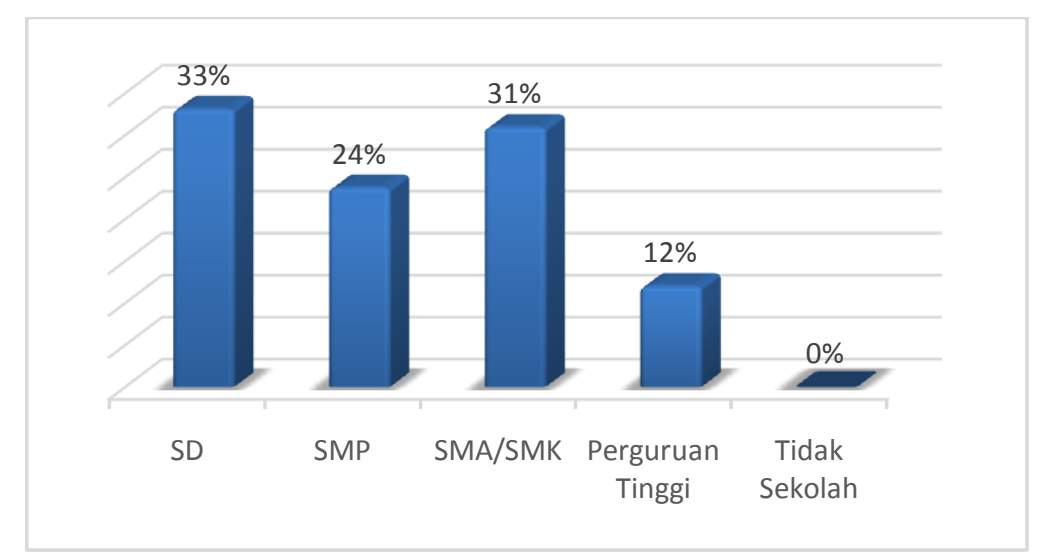

\section{Gambar 2. Tingkat Pendidikan Masyarakat Desa Kebumen}

Berdasarkan hasil penelitian diatas bahwa dari 320 responden yang paling tinggi presentase pendidikannya yaitu tingkat SD dengan presentase sebesar 33\% (106 orang). Kemudian tingkat pendidikan selanjutnya yaitu SMA/SMK presentasenya sebesar 31\% (99 orang). Tingkat SMP presentasenya sebesar 24\% ((76 orang), dan tingkat Perguruan Tinggi sebesar 12\% (39 orang). Dari hasil tersebut dapat dilihat bahwa tingkat pendidikan masyarakat di Desa Kebumen hanya mencapai tingkat SD. Banyaknya masyarakat yang tidak melanjutkan pendidikan ke tingkat selanjutnya karena kurangnya kesadaran masyarakat akan pentingnya pendidikan. Namun, pada saat ini masyarakat sudah beranggapan bahwa pendidikan itu sangat penting untuk kedepannya agar mendapatkan pekerjaan yang lebih baik. Masyarakat yang pendidikannya hingga ke tingkat Perguruan Tinggi hanya sebagian kecil saja, dikarenakan masyarakat yang mencapai pendidikan tinggi biasanya memiliki perekonomian yang lumayan tinggi. Kemudian, jika dilihat dari gambar diatas sudah tidak ada masyarakat yang tidak bersekolah, walaupun hanya mencapai tingkatan atau tamatan SD. 


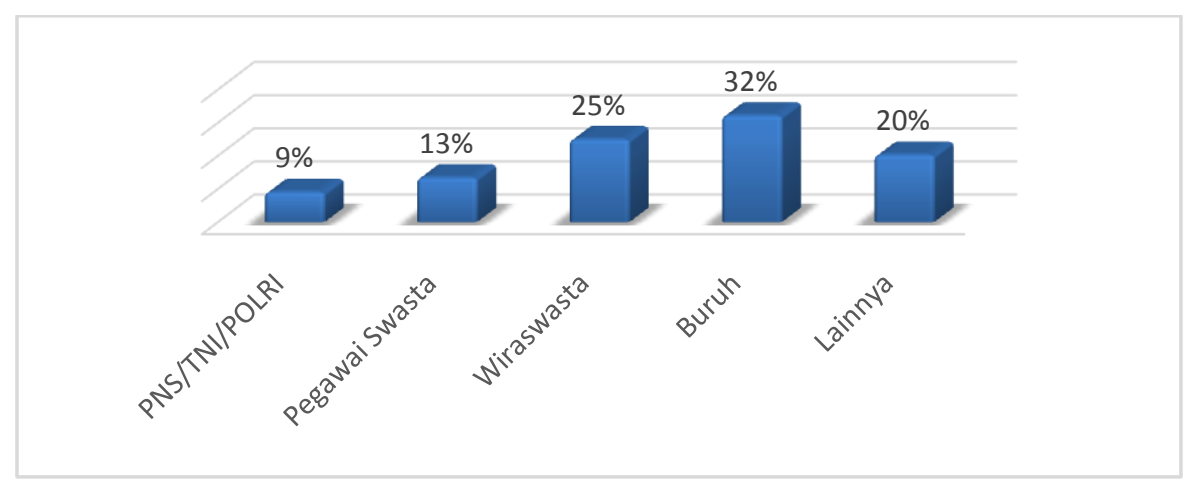

\section{Gambar 3. Jenis Pekerjaan Masyarakat Desa Kebumen}

Berdasarkan hasil penelitian diatas bahwa dari 320 responden yang paling tinggi presentase jenis pekerjaan yaitu buruh dengan presentase sebesar 32\% (103 orang). Kemudian jenis pekerjaan selanjutnya yaitu wiraswasta dengan presentase sebesar $25 \%$ (80 orang). Jenis pekerjaan lainnya berupa pekerja serabutan, pensiunan, ibu rumah tangga, bahkan tidak bekerja presentasenya sebesar 20\% (65 orang). Pegawai swasta presentasenya sebesar 13\% (43 orang) dan pekerja negeri sipil sebesar 9\% (29 orang). Dari hasil tersebut dapat dilihat bahwa rata-rata pekerjaan masyakat Desa Kebumen banyak bekerja sebagai buruh tani maupun buruh pabrik. Hal ini dikarenakan kondisi wilayah di daerah tersebut termasuk daerah persawahan dan perkebunan. Daerah Kecamatan Banyubiru lumayan dekat dengan Kota Salatiga dan Kabupaten Semarang yang lumayan banyak terdapat industri/pabrik. Kemudian wilayah Kecamatan Banyubiru termasuk wilayah yang banyak tempat rekreasinya, dengan itu masyarakat memanfaatkan keadaan dengan cara berjualan maupun membuka tempat rekreasi baru agar para pengunjung ramai berdatangan ke daerah tersebut. Masyarakat yang bekerja sebagai negeri sipil presentasenya paling kecil, hal ini dikarenakan rendahnya tingkat pendidikan di Desa Kebumen. 


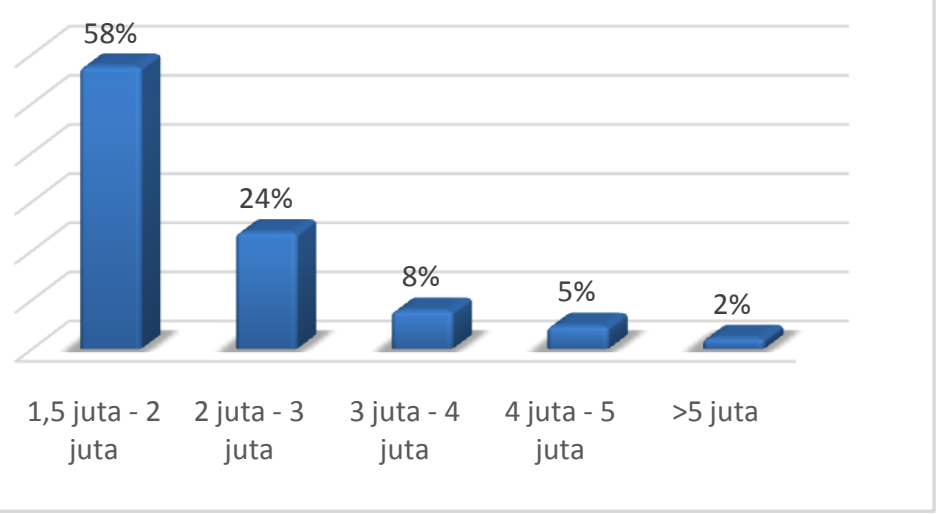

\section{Gambar 4. Tingkat Pendapatan Masyarakat Desa Kebumen}

Berdasarkan hasil penelitian diatas bahwa dari 320 responden yang paling tinggi presentase tingkat pendapatan yang paling tinggi presentasenya yaitu kisaran 1,5-2 juta sebesar 58\% (185 orang). Sebenarnya kisaran tersebut tidak pasti sama dengan pendapatan masyarakat di Desa Kebumen dikarenakan banyak masyarakat yang sebenarnya memiliki pendapatan kurang dari 1 juta dan pendapatan tersebut kadang-kadang juga tidak menentu. Kemudian pendapatan kisaran 2-3 juta memiliki presentase sebesar $24 \%$ (76 orang). Kisaran 3-4 juta sebesar 8\% (24 orang), kisaran 4-5 juta 5\% (15 orang), dan kisaran >5 juta sebesar 2\% (7 orang). Banyaknya masyarakat yang bekerja sebagai buruh membuat kisaran pendapatan rata-rata masyarakat hanya mecapai 1,5-2 juta saja, bahkan kurang dari 1 juta perbulan. Pemenuhan kebutuhan sehari-hari di Desa Kebumen bisa dikatakan belum cukup, karena rendahnya tingkat pendapatan di daerah tersebut.

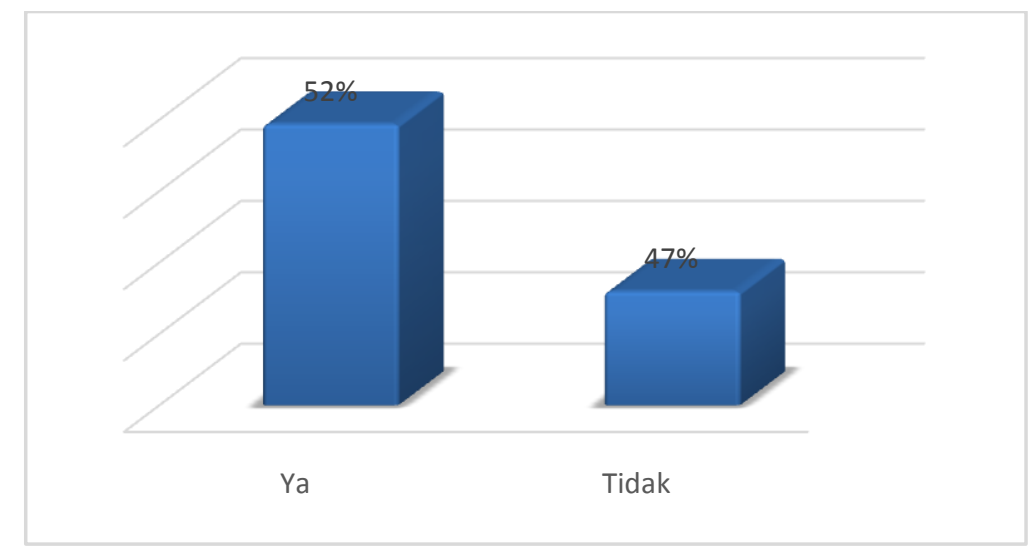

Gambar 4. Kepemilikan Asuransi Kesehatan Desa Kebumen 
Berdasarkan hasil penelitian diatas bahwa dari 320 responden yang memiliki asuransi kesehatan sebanyak 166 orang (52\%) dan yang tidak memiliki asuransi kesehatan sebanyak 151 orang (47\%). Kepemilikan asuransi kesehatan masyarakat Desa Kebumen tidak terlalu signifikan. Hampir sebagian memiliki asuransi kesehatan dan sebagian lainnya tidak memiliki asuransi kesehatan.Masyarakat yang memiliki asuransi kesehatan biasanya berupa Badan Penyelenggara Jaminan Sosial Kesehatan (BPJS Kesehatan). Kartu BPJS yang dimiliki oleh masyarakat Desa Kebumen biasanya digunakan apabila mereka memerlukan bantuan untuk berobat di rumah sakit/klinik terdekat.

Pemerataan BPJS di Desa Kebumen masih kurang, dikarenakan banyaknya masyarakat yang berpendapat bahwa sampai saat ini masih ada masyarakat Desa Kebumen yang belum menerima maupun mendaftarkan dirinya sebagai peserta BPJS Kesehatan. Faktanya adalah program Jaminan Kesehatan Nasional (JKN) yang sudah berjalan sejak 1 Januari 2014, menargetkan bahwa masyarakat seluruh Indonesia harus memiliki JKN tanpa terkecuali pada tanggal 1 Januari 2019. Tetapi, pada saat ini masih ada masyarakat yang belum mengakses JKN atau BPJS. Sebagian dari mereka ada yang menerima langsung kartu BPJS dari pemerintah dan ada juga yang mendaftar secara pribadi.

Kegunaan BPJS Kesehatan pada saat ini kurang membantu masyarakat untuk berobat di rumah sakit/klinik terdekat. Kesulitan dalam memenuhi segala prasyaratan, serta banyaknya hambatan dalam proses pemakaian kartu BPJS menjadi faktor utama masyarakat khususnya Desa Kebumen untuk tidak lagi menggunakannya. Tetapi, tidak sedikit masyarakat yang beranggapan bahwa BPJS sangat membantu berobat mereka ketika sakit. Bahkan, ada sebagian masyarakat yang beranggapan bahwa mereka tidak membayar sepeser pun untuk kartu BPJS dan proses berobat mereka hingga rawat inap pun gratis tanpa dipungut biaya.

\section{Pengaruh Sosial Ekonomi dan Kepemilikan Asuransi Kesehatan}

Pengaruh sosial ekonomi masyarakat menjadi salah satu faktor yang dapat memengaruhi berbagai kehidupan manusia, contohnya adalah kepemilikan asuransi 
kesehatan masyarakat dari kalangan menengah keatas hingga kebawah. Asuransi kesehatan merupakan salah satu upaya untuk mendekatkan akses masyarakat kecil dalam pelayanan kesehatan. Seperti diketahui, selama ini biaya kesehatan di Indonesia relatif mahal dan masih belum terjangkau bagi sebagian besar masyarakat Indonesia. Tujuan dari asuransi kesehatan adalah membayar biaya rumah sakit, biaya pengobatan dan mengganti kerugian karena cedera akibat kecelakaan atau penyakit (Harton, 1992).

Tabel 1. Hasil Uji F dalam Analisis Regresi Linier Berganda

\begin{tabular}{llllll}
\hline & $\begin{array}{l}\text { Sum of } \\
\text { Squares }\end{array}$ & df & $\begin{array}{l}\text { Mean } \\
\text { Square }\end{array}$ & F & Sig. \\
\hline Regression & 10,111 & 3 & 3,370 & 15,264 & $0,000^{\mathrm{a}}$ \\
\hline Residual & 69,776 & 316 & & & \\
\hline Total & 79,888 & 319 & & & \\
\hline
\end{tabular}

Berdasarkan tabel hasil uji $\mathrm{F}$ dalam regresi linier berganda diatas menunjukkan bahwa nilai F p-value (Sig.) =0,000 $(0,000<0,05)$, sesuai dengan pengambilan keputusan dalam uji F maka dapat disimpulkan bahwa Ho ditolak dan Ha diterima atau dengan kata lain yaitu pendidikan, pekerjaan, dan pendapatan (sosial ekonomi) berpengaruh terhadap kepemilikan asuransi kesehatan masyarakat di Desa Kebumen, Kecamatan Banyubiru. Hasil penelitian ini sejalan dengan penelitian yang dilakuakan oleh Littik, (2005) yang berjudul Faktor-Faktor yang Berhubungan dengan Kepemilikan Asuransi di Provinsi Nusa Tenggara Timur. Hasil tersebut menunjukkan bahwa tingkat pendidikan (semua tipe kecuali JPKM) dan pendapatan (untuk Askes) berhubungan dengan kepemilikan asuransi, masingmasing berniali $p$-value $=0,004$ dan $p$-value $=0,001$.

Berdasarkan analisis diatas menurut peneliti adanya pengaruh sosial ekonomi yang cukup kuat terhadap kepemilikan asuransi kesehatan masyarakat Desa Kebumen, menggambarkan bahwa pendidikan, pekerjaan, pendapatan menjadi sebagian faktor yang mendukung memiliki atau tidaknya asuransi kesehatan terutama BPJS. Banyak masyarakat yang belum memahami atau 
mengetahui bahwa BPJS sebagian dari asuransi kesehatan yang dibuat oleh pemerintah dengan kategori maupun kelas yang berbeda-beda. Dengan adanya BPJS tentunya dapat memudahkan atau meringkankan beban masyarakat ekonomi kebawah dalam berobat. Masyarakat yang berpendidikan hingga tamatan SD, dengan pekerjaan sebagai buruh serta memiliki pendapatan kisaran kurang dari 1,5 juta mendominasi kepemilikan asuransi kesehatan di Desa Kebumen.

Kepemilikan asuransi kesehatan swasta seperti Prudential, AXA, Manulife, Allianz, Sinarmas dan lain sebagainya masih sangat jarang di daerah tersebut. Ratarata yang memiliki asuransi kesehatan seperti contoh diatas adalah kalangan pegawai negeri sipil, tetapi asuransi tersebut kurang diperlukan oleh mereka karena adanya kartu BPJS yang menurut mereka lumayan membantu. Tingginya biaya yang dikeluarkan untuk membayar asuransi kesehatan swasta menjadi alasan bagi masyarakat untuk tidak memiliki asuransi tersebut. Beberapa masyarakat yang memiliki ekonomi keatas tidak ingin mendaftarkan atau memiliki asuransi kesehatan swasta dikarenakan masyarakat Desa Kebumen lebih suka untuk membayar langsung apabila ada salah satu keluarganya yang sakit. Proses klaim yang cukup rumit menjadikan beberapa dari masyarakat yang berekonomi tinggi enggan memiliki asuransi kesehatan swasta. Menurut masyarakat Desa Kebumen lebih baik pendapatannya diinvestasikan dengan hal atau benda lain.

\section{SIMPULAN}

Berdasarkan hasil penelitian dapat disimpulkan bahwa yang memiliki asuransi kesehatan sebanyak 166 orang (52\%). Asuransi kesehatan yang dimiliki oleh masyarakat Desa Kebumen rata-rata adalah BPJS. Adanya pengaruh sosial ekonomi (pendidikan, pekerjaan, pendapatan) terhadap kepemilikan asuransi kesehatan dengan nilai p-value 0,000 pada masyarakat Desa Kebumen, Kecamatan Banyubiru, Kabupaten Semarang.

\section{UCAPAN TERIMA KASIH}

Peneliti mengucapkan terima kasih kepada masyarakat Desa Kebumen, Kecamatan Banyubiru, Kabupaten Semarang yang sudah mengizinkan serta 
membantu peneliti untuk menyelesaikan tugas akhir PKL 2 (Perkuliahan Kerja Lapangan), kemudian kepada dosen pembibing yaitu Zaid Ali Wardhana, S.Pd, M.Pd. yang telah membimbing dan membantu peneliti dalam pembuatan jurnal maupun laporan, serta teman-teman Pendidikan Geografi UMS angkatan 2017.

\section{DAFTAR PUSTAKA}

Harton, R. 1992. Hukum Asuransi dan Perusahaan Asuransi. Jakarta: Sinar Grafika.

Kemenkes. 2017. "Profil Kesehatan Provinsi Jawa Tengah Tahun 2017" dalam http://www.depkes.go.id/resources/download/profil/PROFIL_KES_PROVINSI_20 17/13 Jateng 2017.pdf. Diakses Mei 2017.

Littik, Serlie. 2007. "Faktor-Faktor yang Berhubungan dengan Kepemilikan Asuransi" dalam Jurnal MKM Vol.03 No.02, Desember 2007.

Maharani, P. V. 2015. "Analisis Faktor-Faktor yang Mempengaruhi Masyarakat di Kota Singaraja Memiliki Program Asuransi Unitlink" dalam Jurnal Pendidikan Ekonomi Vol.05 No.01, Tahun 2015.

Sari, K. 2017. Perkembangan Asuransi Kesehatan Swasta di Indonesia Tahun 2012-2016. Jurnal Ekonomi Kesehatan Indonesia Vol.02. No.02, Tahun 2018.

Siregar, S. 2013. Metode Penelitian Kuantitatif Dilengkapi Perbandingan Perhitungan Manual \& SPSS. Jakarta: Kencana Prenadamedia Group. 